\title{
On the conductivity of $\mathrm{KBaPO}_{4}$ and its decomposition in steam and water
}

\author{
Aleksander A. Elstad, ${ }^{1}$ Kevin Nguyen, ${ }^{1}$ Sabrina Sartori, ${ }^{2}$ Truls Norby ${ }^{1}{ }^{*}$ \\ ${ }^{1}$ Department of Chemistry, University of Oslo, Centre for Materials Science and \\ Nanotechnology, FERMiO, Gaustadalléen 21, NO-0349 Oslo, Norway \\ ${ }^{2}$ Department of Technology Systems, Section for Energy Systems, University of Oslo, POB \\ 70, NO-2027 Kjeller, Norway \\ *truls.norby@kjemi.uio.no
}

\begin{abstract}
$\mathrm{KBaPO}_{4}$ - recently reported to hydrate in steam at $80^{\circ} \mathrm{C}$ into a novel low-temperature protonic conductor - was synthesized by a solid state reaction and its electrical properties characterized by impedance spectroscopy. At high temperatures the conductivity of $\mathrm{KBaPO}_{4}$ was low (order of $10^{-6} \mathrm{~S} / \mathrm{cm}$ at $600^{\circ} \mathrm{C}$ ) and not significantly different in dry and wet atmospheres, suggesting that $\mathrm{KBaPO}_{4}$ does not take up and conduct protons to any significant extent under these conditions. It was also independent of oxygen partial pressure and increased by acceptor doping ( $\mathrm{K}$ excess), suggesting that the transport is ionic and by an effectively positive charge carrying defect. Impedance spectroscopy displayed significant grain boundary series resistance, and the bulk and grain boundaries displayed activation energies of approximately 110 and $120 \mathrm{~kJ} / \mathrm{mol}$, respectively. At lower temperatures, the conductivity increased, typical of transport in adsorbed water in a porous sample. Exposure of $\mathrm{KBaPO}_{4}$ to steam at $80^{\circ} \mathrm{C}$ resulted in decomposition into $\mathrm{Ba}_{3}\left(\mathrm{PO}_{4}\right)_{2}$ and a liquid phase, presumably a molten hydrate of $\mathrm{K}_{3} \mathrm{PO}_{4}$. We thus suggest that what literature proposes as protonic conduction in steamed $\mathrm{KBaPO}_{4}$ in fact represents transport of $\mathrm{K}^{+}, \mathrm{OH}^{-}$and $\mathrm{HPO}_{4}{ }^{2-}$ ions in the molten hydrate of the decomposition product $\mathrm{K}_{3} \mathrm{PO}_{4}$ held inside porous $\mathrm{Ba}_{3}\left(\mathrm{PO}_{4}\right)_{3}$.
\end{abstract}

\section{Introduction}

In the continuous efforts to identify novel solid-state electrolytes for electrochemical energy conversion under ambient or moderately elevated temperatures, protonic conduction is 
explored in many materials. These may contain protons inherently, e.g. solid acids like $\mathrm{CsHSO}_{4}$ [1] which become proton conducting through order-disorder phase transitions, or they have protons introduced as defects by hydration from ambient water vapour, e.g. Ydoped $\mathrm{BaZrO}_{3}$ [2] and Ca-doped $\mathrm{LaPO}_{4}$ [3] and many more acceptor-doped oxides and oxyacid salts.

Recently, Goodenough and Singh reported briefly - as part of a review paper [4] - their finding that $\mathrm{KBaPO}_{4}$ (which they refer to as $\mathrm{BaKPO}_{4}$ ) takes up water and becomes amorphous in steam at $80^{\circ} \mathrm{C}$, whereafter it exhibits what they suggest is protonic conduction in the temperature range around and below this temperature. We have attempted to reproduce these results and to add to the understanding of the processes behind the observed conduction, by synthesis of $\mathrm{KBaPO}_{4}$, fabrication of disk samples with $\mathrm{Pt}$ paste electrodes, impedance spectroscopy at different water vapour and oxygen activities, hydration in steam, and characterization with scanning electron microscopy (SEM) and X-ray diffraction (XRD).

Follow-up conductivity measurements on $1 \%$ acceptor-doped ( $\mathrm{K}$ excess) $\mathrm{KBaPO}_{4}$ and on decomposition products were also made to shed further light on conductivity mechanisms.

\section{Experimental}

$\mathrm{KBaPO}_{4}$ was synthesized from $\mathrm{KH}_{2} \mathrm{PO}_{4}$ (>99.5\%, Merck) and $\mathrm{BaCO}_{3}$ (99.98\%, Sigma Aldrich) in a 1:1 molar ratio. The reagents were mixed and ball milled (Retsch PM100, agate vial and balls; $33.6 \mathrm{~g}$ balls for $2.5 \mathrm{~g}$ powder, rpm of 250) in isopropanol for $1 \mathrm{~h}$. The mixture was subsequently dried in a beaker at $110^{\circ} \mathrm{C}$ and then calcined in an alumina crucible at $1000^{\circ} \mathrm{C}$ for $6 \mathrm{~h}$. The resulting product was analysed by XRD (MiniFlex 600 BenchTop XRD, Rigaku, radiation $\mathrm{CuK}_{\alpha 1}$ and $\mathrm{CuK}_{\alpha 2}, \lambda=1.5406$ and $1.5444 \AA$, flat plate geometry, $2 \theta$ range from $10^{\circ}$ to $\left.90^{\circ}, \Delta 2 \theta=0.1^{\circ}\right)$ ), showing single-phase $\mathrm{KBaPO}_{4}$, isostructural with $\beta-\mathrm{K}_{2} \mathrm{SO}_{4}$ with an orthorhombic space group Pmcn.[5]

An acceptor-doped sample with 1 mol\% $\mathrm{K}$ excess was made by replacing $1 \mathrm{~mol} \% \mathrm{BaCO}_{3}$ with $0.5 \mathrm{~mol} \% \mathrm{~K}_{2} \mathrm{CO}_{3}$; this maintains phosphate stoichiometry and nominally yields charge compensation by oxygen vacancies, in phosphates commonly in the form of diphosphate ion defects. [6]

The resulting powder was mortared and uniaxially pressed at approximately $150 \mathrm{MPa}$ into disks in a $13 \mathrm{~mm}$ steel die. These were sintered at $950^{\circ} \mathrm{C}$ for $8 \mathrm{~h}$, yielding samples with a final diameter of $12.7 \mathrm{~mm}$ and thickness of $2.9 \mathrm{~mm}$ and a relative density of typically around $73 \%$ 
on the basis of the weight, dimensions, and theoretical density from structural data. [5] The relatively low sintering temperature is chosen to suppress evaporative losses of elements and to keep the sample porous to allow equilibration with the atmosphere at low and moderate temperatures.

For electrical measurements, three layers of Pt-ink (Metalor, Pt A3788A) were painted as circular electrodes of approximately $1 \mathrm{~cm}^{2}$ area on each side of the disks - with intermediate drying at $120^{\circ} \mathrm{C}-$ and final firing at $800^{\circ} \mathrm{C}$ for $6 \mathrm{~h}$. The samples were mounted in a ProboStat $^{\mathrm{TM}}$ measurement cell (NorECs, Norway) with a standard 2-electrode 4-wire setup and connected to a Solartron Instruments 1260 Impedance/Gain-Phase Analyzer. Impedance spectra were recorded within the frequency range $1 \mathrm{MHz}$ to $1 \mathrm{~Hz}$, with an oscillation voltage of $3 \mathrm{~V}$ RMS at temperatures up to $700^{\circ} \mathrm{C}$ in dry $\left(\mathrm{pH}_{2} \mathrm{O} \sim 10^{-5} \mathrm{~atm}\right)$ and humidified $(\sim 3 \%$ $\left.\mathrm{H}_{2} \mathrm{O}, \mathrm{pH}_{2} \mathrm{O} \sim 0.03 \mathrm{~atm}\right)$ air $\left(\mathrm{pO}_{2} \sim 0.21 \mathrm{~atm}\right)$. The spectra were analysed using ZView software (version 3.5a, Scribner Associates Inc.). Alternatively, the conductivity was recorded continuously at $10 \mathrm{kHz}$ to monitor changes with time, temperature, and humidification. Specific conductivities were calculated on basis of the electrode area, sample thickness, and relative density (the latter by a factor of close to 2 ).

$\mathrm{KBaPO}_{4}$ samples were subjected to steam at around $80^{\circ} \mathrm{C}\left(\mathrm{pH}_{2} \mathrm{O} \sim 0.47\right.$ atm), corresponding to the treatment described by Goodenough and Singh.[4] This was done ex situ by hanging a sample right over water held at $80^{\circ} \mathrm{C}$. It was also done in situ during electrical measurements by heating the entire setup and tubing to approximately $82^{\circ} \mathrm{C}$ (to avoid condensation) and flowing air through a water bubble flask placed in a heated circulating bath set at $80^{\circ} \mathrm{C}$. The samples exposed to these treatments were characterised electrically, and by XRD, SEM (Quanta 200 FEG-ESEM, FEI), and X-ray energy-dispersive spectroscopy (EDS, EDAX Pegasus 2200) in the SEM.

\section{Results \& Discussion}

\section{Electrical Measurements on $\mathrm{KBaPO}_{4}$}

Before steam-treatment of the sample, initial electrical measurements were conducted on the sintered $\mathrm{KBaPO}_{4}$ sample with Pt electrodes. Figure 1a shows a typical impedance spectrum for temperatures above $300^{\circ} \mathrm{C}$. The spectra display two semicircles and could be fitted to a model of two series connected impedances attributable to grain interiors (measured and specific geometry-corrected equivalent capacitances of approximately $20 \mathrm{pF}$ and $6 \mathrm{pF} / \mathrm{cm}$, 
respectively) and grain boundaries (measured capacitances of approximately $150 \mathrm{pF}$ ). At these temperatures there were no significant differences in conductivities between dry and humidified atmospheres neither for the grain interior nor grain boundary contributions.

Figure 2 shows the logarithm of the obtained conductivities calculated using the macroscopic sample thickness and electrode area versus inverse absolute temperature. Above $300^{\circ} \mathrm{C}$, the conductivity attributed to grain interior and grain boundaries have activation energies (from analysis of $\ln (\sigma T)$ versus $1 / T)$ of around $110 \mathrm{~kJ} / \mathrm{mol}$ and $120 \mathrm{~kJ} / \mathrm{mol}$, respectively. The slightly higher activation energy of the grain boundary conductance is commonly observed for materials in which the grain boundary resistance stems from depletion of charge carriers in a space charge region adjacent to a net charged grain boundary core.[7, 8] The absence of a significant effect of humidity suggests that there is no significant protonic conductivity in $\mathrm{KBaPO}_{4}$ above $300^{\circ} \mathrm{C}$.

We measured the conductivity of $\mathrm{KBaPO}_{4}$ above $300^{\circ} \mathrm{C}$ in gases with varying partial pressures of oxygen. There was no significant effect (results consequently not plotted) taken to mean that there is no redox-chemistry involved, that there are insignificant concentrations of electronic charge carriers (electrons and holes), and that the conductivity is largely ionic.

In order to obtain further information of the ionic conductivity mechanism, we measured the conductivity of a sample acceptor-doped with $1 \mathrm{~mol} \%$ excess $\mathrm{K}$ nominally charge compensated by oxygen vacancies, likely in the form of diphosphate ion defects [6]. This sample showed a higher conductivity and lower activation energy (results not shown here), still without effect of humidity. As a rule of thumb, increased transport by a lower valent substituent means that the charge carrying charge compensating defect is positive, like oxygen vacancies. The lower activation energy may then reflect a constant charge carrier concentration resulting from the doping. However, oxide ions are covalently bonded in $\mathrm{KBaPO}_{4}$ and not expected to be mobile. Hence an alternative ionic charge carrier may be effectively positive interstitial $\mathrm{K}^{+}$ions.

Below $300^{\circ} \mathrm{C}$, the conductivity became immeasurably small, Figure 2 . Below $150^{\circ} \mathrm{C}$, the conductivity in wet atmosphere became measurable and increased with further decreasing temperatures, a behaviour typical of conduction in physisorbed water in porous ceramic samples.[9, 10] Figure $1 \mathrm{~b}$ shows an impedance spectrum taken at $40^{\circ} \mathrm{C}$ in humidified air. It has similar shape as spectra collected above $300^{\circ} \mathrm{C}$ and to a first approximation with similar capacitances. We may hence again attribute the two contributions to volume transport (now in 
the adsorbed water layer) and transport across grain boundaries. It has been suggested (for another porous ceramic material) that the resistance to transport in adsorbed water across the grain boundaries intersecting the surfaces may stem from space charge from the charged grain boundary penetrating the water layer.[11]

\section{Hydration in steam or water}

A sample of sintered $\mathrm{KBaPO}_{4}$ was subjected to steam of estimated 0.47 atm partial pressure at around $80^{\circ} \mathrm{C}$ for $24 \mathrm{~h}$ in order to investigate the presence of an amorphous proton conducting phase as suggested by Goodenough and Singh.[4] Figures 3 and 4 show micrographs of the sample before and after this steam treatment. The as-sintered sample exhibits a porous ceramic microstructure, confirmed by XRD and EDS to be the $\mathrm{KBaPO}_{4}$-phase, while after steaming, this converts into a new solid phase, appearing as elongated flakes growing inwards from the surface. XRD (Figure 5) and EDS showed that this is $\mathrm{Ba}_{3}\left(\mathrm{PO}_{4}\right)_{2}$. EDS suggested that it has a small content of $\mathrm{K}$, which is expected since it formed from $\mathrm{KBaPO}_{4}$. It is expected from the stoichiometry of the reaction that the other decomposition product is $\mathrm{K}_{3} \mathrm{PO}_{4}$. Its absence in the reacted solid and since the reaction is promoted by the presence of steam, it is likely that it hydrates directly as formed, that the solvation energy drives the reaction, and that it melts into an aqueous solution which has poured out of the sample or into the porous remaining $\mathrm{KBaPO}_{4}$ during the steaming.

The steamed sample was split in two. One half was subjected to another treatment with steam at $80^{\circ} \mathrm{C}$, now for $48 \mathrm{~h}$, whereby it was completely converted to $\mathrm{Ba}_{3}\left(\mathrm{PO}_{4}\right)_{2}$ (Figure 6). The pH of the water underneath the sample was checked, showing a strongly basic reaction, confirming that the basic salt $\mathrm{K}_{3} \mathrm{PO}_{4}$ pours out dissolved in its hydrate water.

The other half of the steamed sample was submerged in purified water at room temperature for $48 \mathrm{~h}$, and also here the decomposition proceeded deeper into the sample, although not as completely as in gaseous steam, see Figure 7.

The $\mathrm{KBaPO}_{4}$ sample that gave rise to the results in Figures 1 and 2 was installed in a heated ProboStat measurement cell and the base unit was heated to $82^{\circ} \mathrm{C}$ to allow in situ electrical conductivity measurements during exposure to steam at $80^{\circ} \mathrm{C}$, corresponding to a water vapour pressure of $0.47 \mathrm{~atm}$. Figure 8 shows the results of continuous measurements of AC conductivity at $1 \mathrm{kHz}$ while the cell was repeatedly fed with high water vapour pressure by heating the humidifier to $80^{\circ} \mathrm{C}$, followed by cooling the humidifier to room temperature (RT). 
During steaming, the conductivity is high, and increasing. We take this to reflect the decomposition into liquid hydrated $\mathrm{K}_{3} \mathrm{PO}_{4}$. By reverting to normal humidity levels by cooling the water bath to room temperature, the conductivity drops, and we consider this to reflect that the $\mathrm{K}_{3} \mathrm{PO}_{4}$ dehydrates and solidifies.

All in all, the results show that $\mathrm{KBaPO}_{4}$ is unstable in water, both in steam at $80^{\circ} \mathrm{C}$ and in water at RT. The reaction can be understood as

$$
3 \mathrm{KBaPO}_{4}(\mathrm{~s}) \stackrel{\mathrm{H}_{2} \mathrm{O}(l)}{\longrightarrow} \mathrm{Ba}_{3}\left(\mathrm{PO}_{4}\right)_{2}(\mathrm{~s})+3 \mathrm{~K}^{+}(\mathrm{aq})+\mathrm{PO}_{4}^{3-}(\mathrm{aq})
$$

Hence, while $\mathrm{KBaPO}_{4}$ is the stable product of the synthesis at high temperatures, where water is evaporated, the solvation of the $\mathrm{K}^{+}$and $\mathrm{PO}_{4}{ }^{3-}$ ions provides the energy to decompose the compound into solid $\mathrm{Ba}_{3}\left(\mathrm{PO}_{4}\right)_{2}$ and an aqueous solution of $\mathrm{K}_{3} \mathrm{PO}_{4}$. The basic nature of the $\mathrm{PO}_{4}{ }^{3-}$ ion furthermore provides the basic reaction of the solution:

$$
\mathrm{PO}_{4}^{3-}(\mathrm{aq})+\mathrm{H}_{2} \mathrm{O}(\mathrm{l}) \leftrightarrow \mathrm{HPO}_{4}^{2-}(\mathrm{aq})+\mathrm{OH}^{-}(\mathrm{aq})
$$

The same happens at $80^{\circ} \mathrm{C}$ in steam: The $\mathrm{KBaPO}_{4}$ decomposes in the presence of steam, but it is less obvious that we obtain $\mathrm{K}_{3} \mathrm{PO}_{4}$ dissolved in water since there is initially no liquid phase there. However, in view of the existence of solid hydrates $\mathrm{K}_{3} \mathrm{PO}_{4} \cdot \mathrm{H}_{2} \mathrm{O}$ and $\mathrm{K}_{3} \mathrm{PO}_{4} \cdot 3 \mathrm{H}_{2} \mathrm{O}$ the reaction product at $80^{\circ} \mathrm{C}$ can be understood as melts of these hydrates. $\mathrm{K}_{3} \mathrm{PO}_{4} \cdot x \mathrm{H}_{2} \mathrm{O}$ melts and dissolves in its own crystal water, a behaviour known for other hydrated salts.

By this we may understand how and where the $\mathrm{K}_{3} \mathrm{PO}_{4}$ component goes - it takes up water and melts in the process of decomposition, gets absorbed into the remaining porous sample and eventually sips out of it as the decomposition completes.

The decomposition is not instantaneous - it requires rearrangement of the ions to form the new structure, leaching out of $\mathrm{K}^{+}$, and a supply of considerable amounts of water, and hence takes place from the external surface and inward - even if the sample is porous and one might expect reaction on all internal surfaces. This may be due to the high concentration of $\mathrm{K}$ inside and high concentration of water outside: These have to interdiffuse through the pores, which takes some time, especially at lower temperature (RT).

The in situ conductivity measurement during steaming suggests that some of the liquid decomposition product remains inside the porous sample. The high conductivity under these conditions observed by us and even higher conductivity reported by Goodenough and Singh[4] is then most likely due to the $\mathrm{K}^{+}$and $\mathrm{OH}^{-}$and phosphate ions in the molten hydrate of $\mathrm{K}_{3} \mathrm{PO}_{4}$. The conductivity is protonic (by $\left.\mathrm{OH}^{-}\right)$but not proton $\left(\mathrm{H}^{+}\right)$conductivity as such. 
Goodenough and Singh state that the conduction takes place in an amorphous phase; this needs not be in disagreement with the presence of a hydrated $\mathrm{K}_{3} \mathrm{PO}_{4}$ phase cooled to $\mathrm{RT}$ for their structural investigation. All in all, we suggest that the conductivity reported by Goodenough and Singh is not proton conductivity in hydrated $\mathrm{KBaPO}_{4}$, but conductivity by $\mathrm{OH}^{-}$and other ions in molten hydrated $\mathrm{K}_{3} \mathrm{PO}_{4}$ as a decomposition product of $\mathrm{KBaPO}_{4}$ in steam.

After complete decomposition in steam at $80^{\circ} \mathrm{C}$, we measured briefly the conductivity of the sample at elevated temperatures in dry and wet air. This may reflect largely the conductivity of solid K-containing $\mathrm{Ba}_{3}\left(\mathrm{PO}_{4}\right)_{2}$, but may also be influenced by remaining $\mathrm{K}_{3} \mathrm{PO}_{4}$. The conductivities were modest, in rough agreement with those reported for the system $\mathrm{Ba}_{3-\mathrm{x}} \mathrm{K}_{\mathrm{x}} \mathrm{H}_{\mathrm{x}}\left(\mathrm{PO}_{4}\right)_{2}$ by Chisholm et al.,[12] and could not have accounted for the high conductivities reported at low temperatures for the steamed $\mathrm{KBaPO}_{4}$ by Goodenough and Singh.

As a final note, it is interesting that decomposition of $\mathrm{KBaPO}_{4}$ in water or steam may provide a low-temperature route to $\mathrm{K}$-doped $\mathrm{Ba}_{3}\left(\mathrm{PO}_{4}\right)_{2}$, and further investigations of this beyond our brief measurements are suggested.

\section{Conclusions}

The conductivity of a porous sample of polycrystalline $\mathrm{KBaPO}_{4}$ has been measured by impedance spectroscopy in wet and dry atmospheres, displaying a modest conductivity with activation energies of around $110 \mathrm{~kJ} / \mathrm{mol}$ at $300-700^{\circ} \mathrm{C}$. This exhibits two time constants in impedance spectra, suggesting contributions from bulk and grain boundaries to the overall impedance. The conductivity is not significantly different in wet and dry atmospheres, suggesting that proton uptake and conductivity is not prominent. The conductivity is furthermore independent of oxygen partial pressure and increases with acceptor doping by $\mathrm{K}$ excess, showing that it is ionic in nature and indicating an effectively positive charge carrying defect.

Below $300^{\circ} \mathrm{C}$ the conductivity in dry atmospheres goes immeasurably low, while the conductivity in wet atmospheres starts to increase with decreasing temperature below $150^{\circ} \mathrm{C}$. This is typical of conduction in physisorbed water on the inner surfaces of the porous sample.

Treatment in steam at $80^{\circ} \mathrm{C}$ or in liquid water at room temperature led to decomposition of the sample into $\mathrm{Ba}_{3}\left(\mathrm{PO}_{4}\right)_{2}$ and what is likely molten hydrated $\mathrm{K}_{3} \mathrm{PO}_{4}$ which eventually leaks out 
of the porous material. On this basis, we suggest that the conduction of $\mathrm{KBaPO}_{4}$ after treatment in steam assigned by Goodenough and Singh to protonic conduction in an amorphous hydrated phase, is in fact conduction by $\mathrm{OH}^{-} \mathrm{K}^{+}$, and $\mathrm{HPO}_{4}{ }^{2-}$ ions in molten hydrated $\mathrm{K}_{3} \mathrm{PO}_{4}$ remaining from decomposition of the starting compound in steam.

\section{References}

1. Haile, S.M., Boysen, D.A., Chisholm, C.R.I., Merle, R.B., Solid acids as fuel cell electrolytes. Nature, 2001. 410: p. 910-913.

2. Kreuer, K.D., Proton-Conducting Oxides. Annual Review of Materials Research, 2003. 33: p. 333-359.

3. Norby, T. and N. Christiansen, Proton conduction in Ca- and Sr-substituted LaPO4. Solid State Ionics, 1995. 77: p. 240-243.

4. Goodenough, J.B. and P. Singh, Review - Solid Electrolytes in Rechargeable Electrochemical Cells. Journal of The Electrochemical Society, 2015. 162(14): p. A2387-A2392.

5. Masse, R. and A. Durif, Chemical Preparation and Crystal Structure Refinement of KBaPO4 Monophosphate. Journal of Solid State Chemistry, 1987. 71: p. 574-576.

6. Sharova, N., H. Fjellvåg, and T. Norby, Structure, defect chemistry, and proton conductivity in nominally Sr-doped Ba3La(PO4)3. Solid State Ionics, 2009. 180: p. 338-342.

7. Chen, C.-T., C.E. Danel, and S. Kim, On the origin of the blocking effect of grainboundaries on proton transport in yttrium-doped barium zirconates. Journal of Materials Chemistry, 2011. 21(14): p. 5435-5442.

8. Guo, X. and J. Maier, Grain Boundary Blocking Effect in Zirconia: A Schottky Barrier Analysis. Journal of The Electrochemical Society, 2001. 148(3): p. E121-E126.

9. Köck, E.-M., et al., Structural and Electrochemical Properties of Physisorbed and Chemisorbed Water Layers on the Ceramic Oxides Y2O3, YSZ and ZrO2. ASC Applied Materials \& Interfaces, 2016. 8(25): p. 16428-16443.

10. Scherrer, B., et al., On Proton Conductivity in Porous and Dense Yttria Stabilized Zirconia at Low Temperature. Advanced Functional Materials, 2013. 23(15): p. 19571964.

11. Stub, S.Ø., Vøllestad, E., Rørvik, P.M., Norby, T., On the interaction of grain boundaries and protonic surface transport in porous oxides. Under publication.

12. Chisholm, C.R.I., et al., Engineering the Next Generation of Solid State Proton Conductors: Synthesis and Properties of Ba3-xKxHx(PO4)2. Chemistry of Materials, 2010. 22(3): p. 1186-1194. 

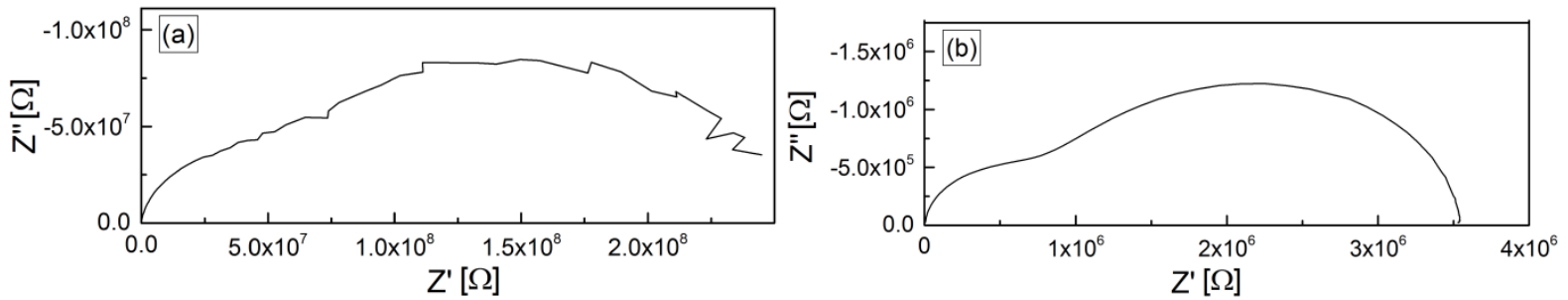

Figure 1: Impedance spectra of sintered $\mathrm{KBaPO}_{4}$ with Pt electrodes at $400^{\circ} \mathrm{C}$ in dry air (a) and at $40^{\circ} \mathrm{C}$ in humidified $\left(\sim 3 \% \mathrm{H}_{2} \mathrm{O}\right)$ air $(\mathrm{b})$.

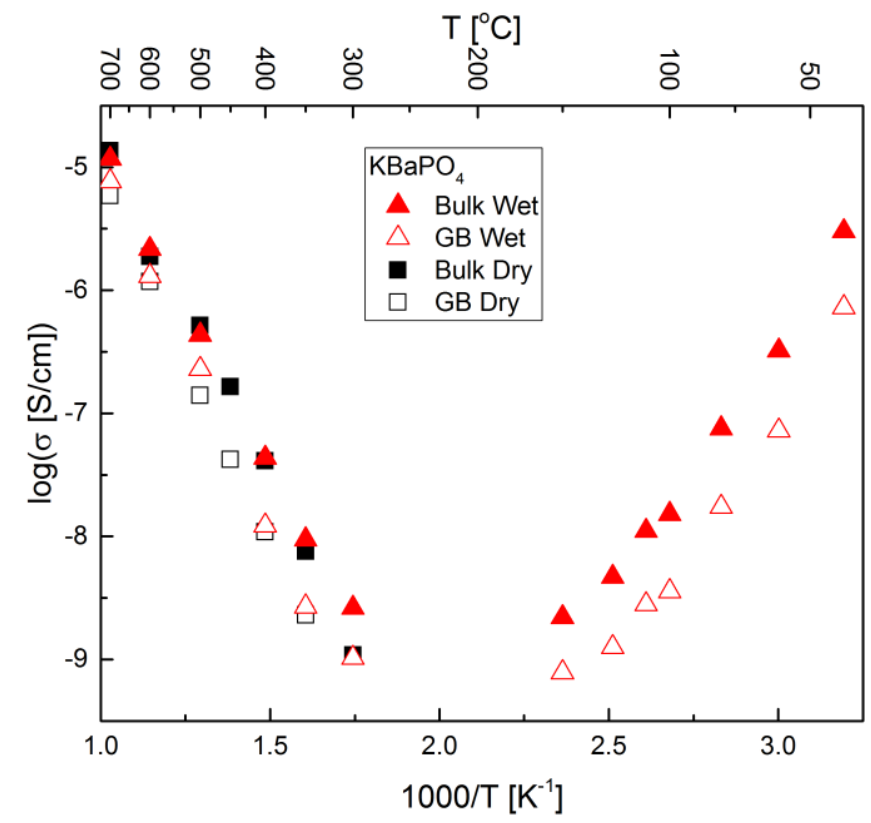

Figure 2: Arrhenius plot of the logarithm of bulk and grain boundary (GB) conductivities of the porous sintered sample of $\mathrm{KBaPO}_{4}$ in dry and humidified air $\left(p \mathrm{H}_{2} \mathrm{O}=0.03\right.$ atm $)$ ss inverse absolute temperature. The plotted conductivities are specific for the porous sample as such, obtained using the macroscopic electrode area and sample thickness, and corrected for porosity. 


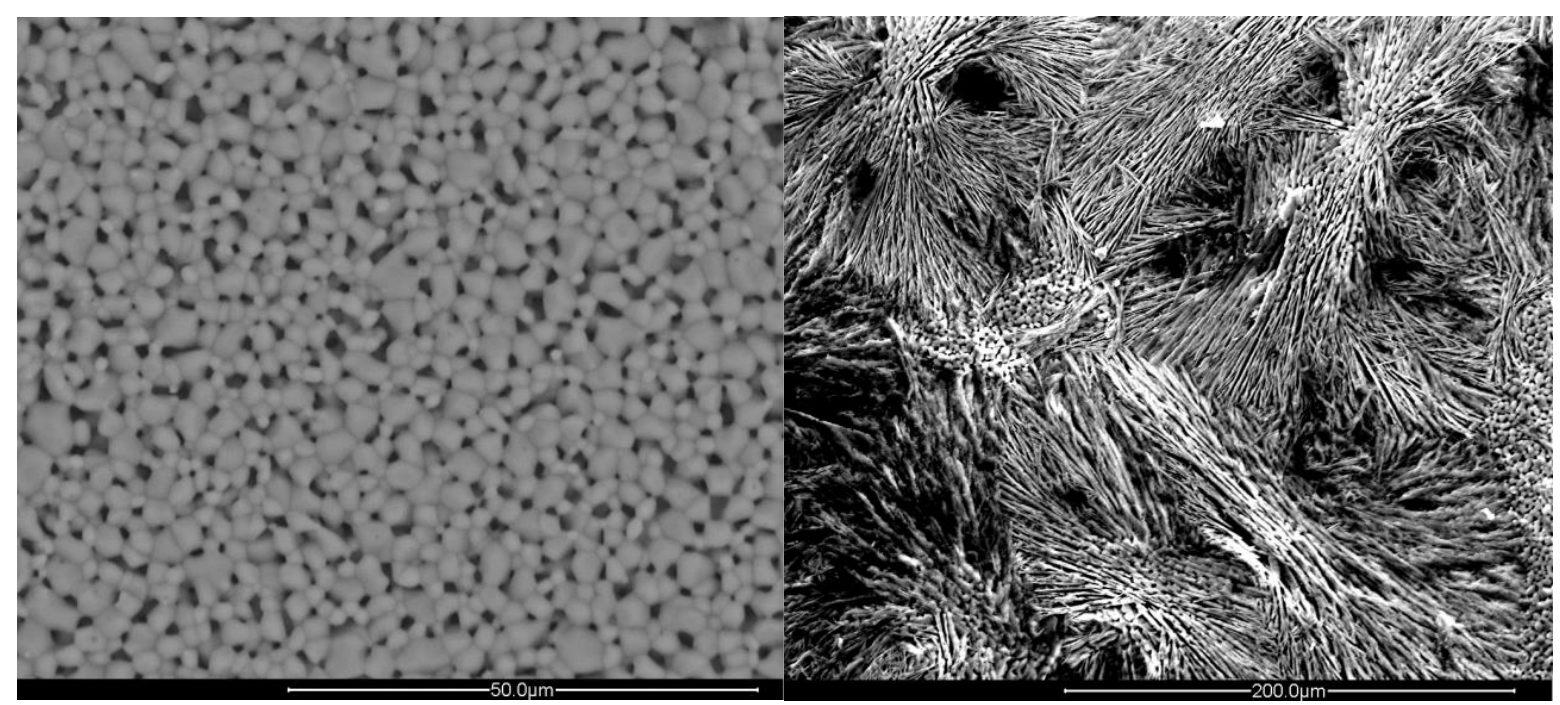

Figure 3. SEM micrographs of surfaces of porous sintered $\mathrm{KBaPO}_{4}$ before (left) and after (right) annealing in steam (approximately $80^{\circ} \mathrm{C}, \mathrm{pH}_{2} \mathrm{O}=0.47$ atm) for $24 \mathrm{~h}$. The steamed sample contains $\mathrm{Ba}_{3}\left(\mathrm{PO}_{4}\right)_{2}$ in addition to regions of unreacted porous $\mathrm{KBaPO}_{4}$.

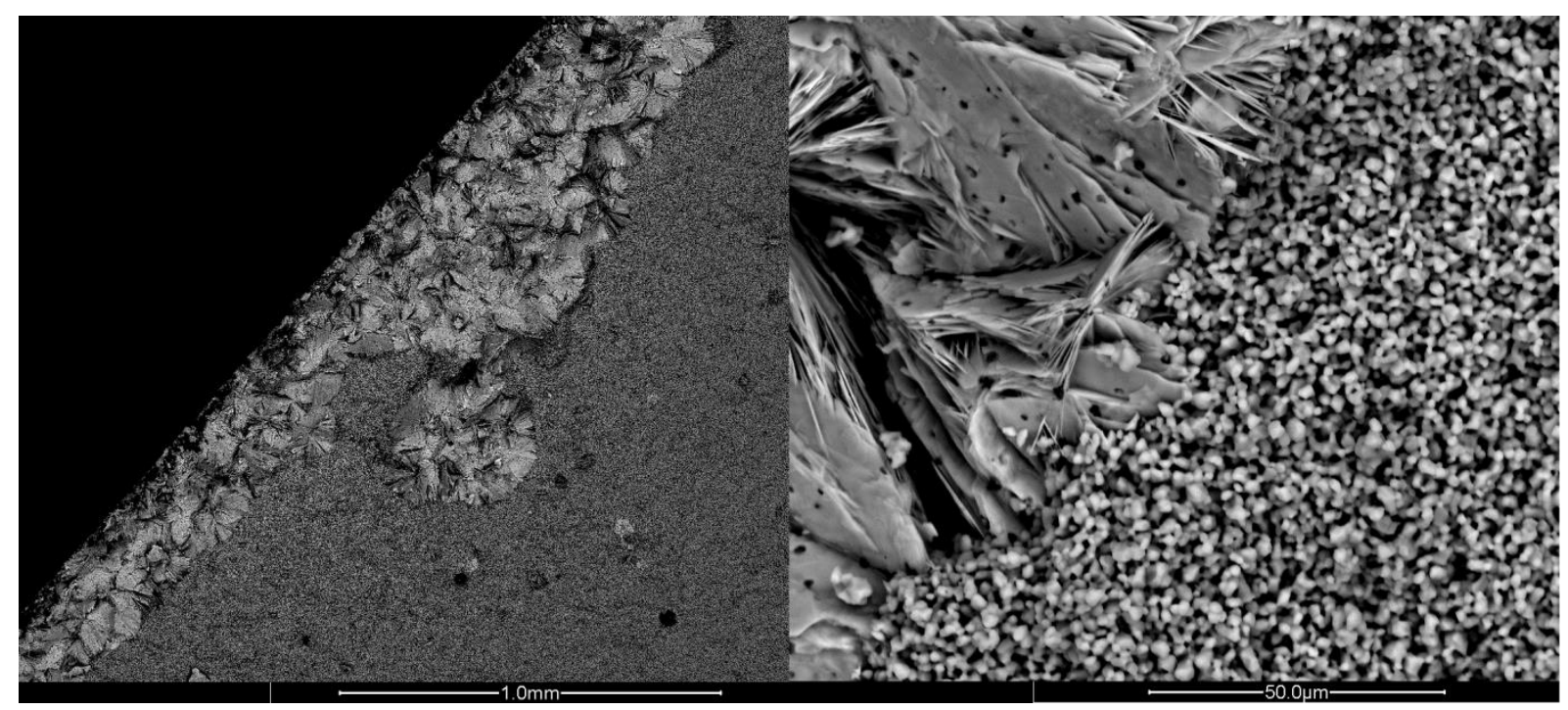

Figure 4. SEM micrographs of cross-sections of porous sintered $\mathrm{KBaPO}_{4}$ after annealing in steam at low (left) and high (right) resolution, showing that the decomposition to $\mathrm{Ba}_{3}\left(\mathrm{PO}_{4}\right)_{2}$ starts from the surface, leaving unreacted porous $\mathrm{KBaPO}_{4}$ in the interior. 


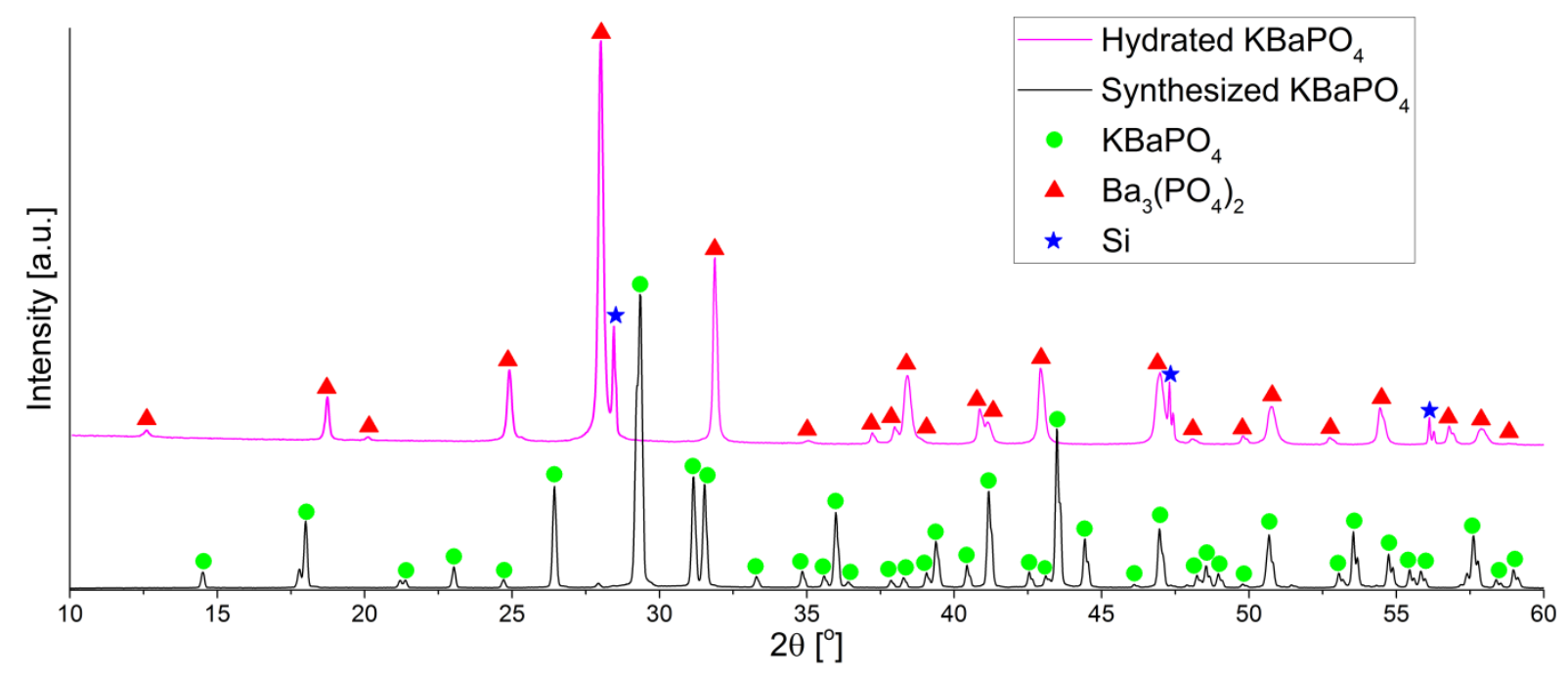

Figure 5. XRD patterns of as-synthesized $\mathrm{KBaPO}_{4}$ and $\mathrm{KBaPO}_{4}$ post-hydration, compared with PDF patterns for $\mathrm{KBaPO}_{4}$ (01-084-1462), $\mathrm{Ba}_{3}\left(\mathrm{PO}_{4}\right)_{2}(01-073-2805)$ and $\mathrm{Si}$ (00-0271402). Si was added as a reference to the hydrated $\mathrm{KBaPO}_{4}$ before $\mathrm{XRD}$ analysis.

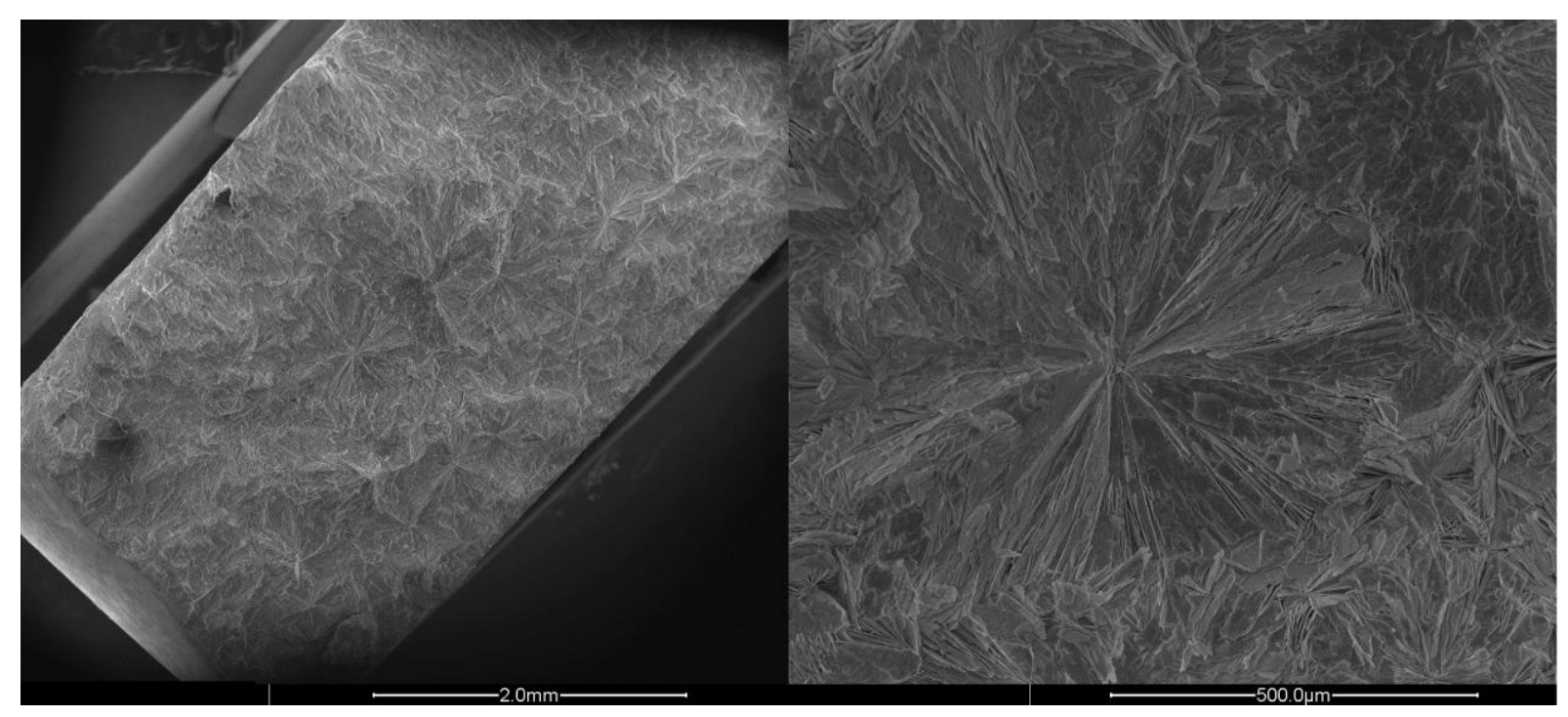

Figure 6: SEM micrographs of the cross-section of the $\mathrm{KBaPO}_{4}$ sample after treatment in steam for an additional 48 hours following the initial 24 hour treatment, showing complete decomposition into $\mathrm{Ba}_{3}\left(\mathrm{PO}_{4}\right)_{2}$. 


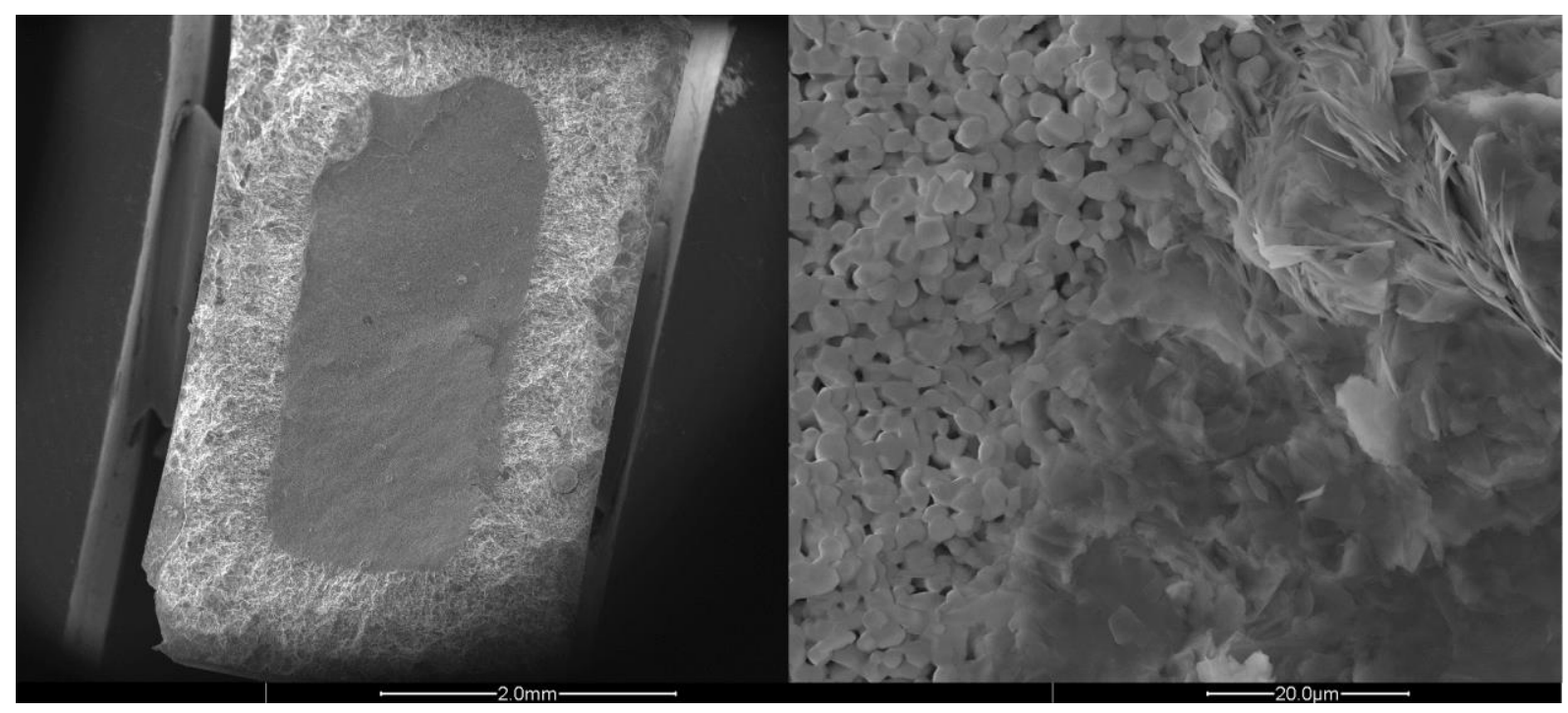

Figure 7: SEM images of the cross-section of the $\mathrm{KBaPO}_{4}$ sample submerged in water for an additional 48 hours following the initial 24 hour treatment in steam, showing an outer decomposed shell and an intact interior.

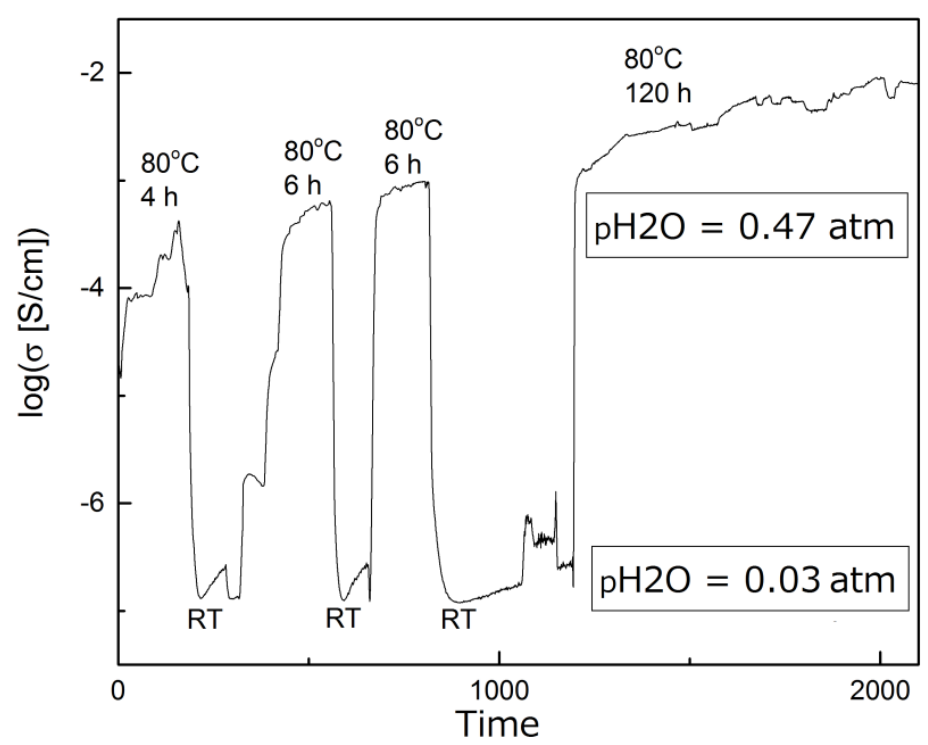

Figure 8: Isothermal AC conductivity of $\mathrm{KBaPO}_{4}$ at slightly above $80^{\circ} \mathrm{C}$ during intermittent exposure to steam from a humidifier at $80^{\circ} \mathrm{C}$ yielding a water vapour partial pressure of 0.47 atm, and humid gas from the same bath set to room temperature (RT) yielding about 0.03 atm of water vapour. 